\title{
Internet functions in marketing: multicriteria ranking of agricultural SMEs websites in Greece
}

Georgios Tsekouropoulos ${ }^{1}$, Zacharoula Andreopoulou ${ }^{2}$, Christiana Koliouska ${ }^{3}$, Theodoros Koutroumanidis ${ }^{4}$, Christos Batzios ${ }^{5}$, Vagis Samathrakis ${ }^{6}$

\section{N F O \\ Received 16 July 2013 \\ Available on-line 31 Dec 2013 \\ Responsible Editor: Rajkai, K. \\ Keywords: \\ e-marketing, internet,database, e-commerce, agro-food and drink sector.}

\begin{abstract}
A B S T R A C T
The invasion of new technologies combined with the high cost for running shop force enterprises to search for new sales methods. Network applications and ICT (Information and Communication Technology) can help achieve e-commerce goals. In Greece, many enterprises in the agro-food and drink sectors are already present on the internet. This paper studies the adoption of e-commerce on websites that support e-commerce activities within the agro-food and drink sectors. Therefore, the paper aims to identify and evaluate their qualitative and quantitative content characteristics, rank them according to 6 content characteristics/criteria using the multicriteria method of PROMETHEE II and classify them in groups of similar adoption. The findings of this study reveal the rate of adoption of e-commerce in the sectors and can serve as a valuable model for the designers of websites that promote e-commerce activities within the wider areas of food and drinks
\end{abstract}

\section{Introduction}

Nowadays, the internet has emerged as a key channel for enterprises (Soto-Acosta and MeronoCerdan, 2006) as it has become a means of promotion and consequently, an effective business tool (Tsekouropoulos et al., 2012a; Tsekouropoulos et al., 2012b). Enterprises use the internet not only for retrieving information and marketing but also for the enhancement of their communication with business-partners and customers (Tsekouropoulos, Tzimitra-Kalogianni, and Manos, 2005).

The world of business is changing rapidly (Marri, Irani, and Gunasekaran, 2007). Traditional manufacturing and service environments have been transformed into more physically distributed enterprise environments, which include supply chains, electronic commerce (e-commerce), electronic marketing (e-marketing) and virtual enterprises (Gunasekaran and Ngai, 2007). These portals can extend their reach to potential customers worldwide (Chan and Chung, 2002) through the use of the internet as a marketing tool. As technology, market and regulation conditions change rapidly, ebusiness companies frequently have to reinvent their business models (Reuver, Bouwman, and

${ }^{1}$ Georgios Tsekouropoulos

A.T.E.I. of Thessaloniki, Greece

geotsek@mycosmos.gr

${ }^{2}$ Zacharoula Andreopoulou

Aristotle University of Thessaloniki, Greece

randreop@for.auth.gr

${ }^{3}$ Christiana Koliouska

Aristotle University of Thessaloniki, Greece

ckolious@for.auth.gr

${ }^{4}$ Theodoros Koutroumanidis

Democritus University of Thrace, Greece

tkoutrou@agro.duth.gr

${ }^{5}$ Christos Batzios

Aristotle University of Thessaloniki, Greece

batzios@vet.auth.gr

${ }^{6}$ Vagis Samathrakis

Alexander Technological Educational Institute of Thessaloniki, Greece

sbagis@farm.teithe.gr 
Maclness, 2009). Thus, the internet has become a major resource in modern business and many businesses are creating a web presence (Calitz and Scheepers, 2002).

The enterprises aim at their participation in the internet society since the benefits are high and electronic systems are ready to serve customers all over the world 24 hours per day 7 days a week (Andreopoulou, 2012), when the cost keeps decreasing. Enterprises and individuals have lately become familiar to do business transactions the way and time they prefer, thus, long-established enterprises in all areas of interest are continually searching to enable the provision through internet for their products and services (Krueger and Swatman, 2004). Dialog between two parties, the company that offers a service or a product and the customers, represents a vitally important element of relationship marketing which helps to build customer loyalty. A great advantage of a webpage consists in the possibility to update it with current information whenever it is required.

For consumers, internet can reduce clutter, which could mean that content will more closely match their interests; while for sellers it facilitates a one-to-one marketing approach, allowing them to target each individual with a specific message (O'Connor, 2007). It plays an important role mediating between customers and enterprises as a place for information acquisition and business transactions (Liang and Law, 2003).

According to recent studies, the internet is most effective when used as an advertising and marketing tool (Cai, Card, and Cole, 2004; Garces et al., 2004; Law and Hsu, 2005; Lee, Cai, and O'Leary, 2006; Bui, Le, and Jones, 2006; Buhalis and Law, 2008).

\subsection{E-marketing}

E-marketing is a subset of e-Business that utilizes electronic medium to perform marketing activities and achieve desired marketing objectives for an organization (Petrovic, 2010). E-marketing can be defined as the use of internet and related digital technologies to achieve marketing objectives and support the modern marketing concept (Eszes, 2010). It includes both direct response marketing and indirect marketing elements, and uses a range of technologies to help connect businesses to their customers. By such a definition, e-marketing encompasses all the activities a business conducts via the worldwide web with the aim of attracting new business, retaining current business and developing its brand identity (Quirk eMarketing, 2006). E-commerce is also a part of e-business. It is the purchasing, selling, and exchanging of goods and services over computer networks, such as the internet, through which transactions or terms of sale are performed electronically (DigitSmith, 2006). The aim of ebusiness applications is to make businesses agile by supporting dynamic internal and external boundary-crossing business processes (Baghdadi, 2006).

The growth of e-business presents enterprises with both opportunities and challenges. In this environment enterprises need timely and sound e-business strategies (Ha and Forgionne, 2008). Emarketing gives business of any size access to the mass market at an affordable price and allows truly personalized marketing. Specific benefits of e-marketing include (Department of Trade and Industry of United Kingdom, 2004; The National B2B Centre, 2011):

a. Global reach. A website allows finding new markets and trading globally.

b. Lower cost. A properly planned and effectively targeted e-marketing campaign can reach the right customers at a much lower cost than traditional marketing methods.

c. Trackable, measurable results. Web-analytics and other online metric tools make it easier to establish how effective the campaign has been.

d. 24-Hour marketing. With a website the customers can find out about the products even if the office is closed.

e. Shorter lead times. If there is a website or an e-mail template, the reaction to events will be more quickly, giving a much more contemporary feel.

f. A level playing field. With a well-designed website, the enterprise could look like professional and credible as the larger competitors. 
g. Personalization. If the customer database is linked to the website, then whenever someone visits the site, can be greeted with targeted offers. DataBase Management System (DBMS) is a software package that allows data to be effectively stored, retrieved and manipulated (Andreopoulou, Koliouska and Tsekouropoulos, 2012).

h. Openness. By having a social media presence and managing it carefully, the entrepreneur can built customer loyalty and create a reputation for being easy to engage with.

i. Social currency. E-marketing lets the entrepreneur create engaging campaigns which can gain social currency-being passed from user to user and becoming viral.

j. Improved conversion rates. If the enterprise has a website, then the customers are only ever a few clicks away from completing a purchase.

Together, all of these aspects of e-marketing have the potential to add up to more sales.

However, e-marketing does have few disadvantages such as (Eszes, 2010): lack of personal approach, dependability on technology, security-privacy issues, maintenance costs due to a constantly evolving environment, higher transparency of pricing, increased price competition and worldwide competition through globalization.

Small and Medium-sized Enterprises (SMEs) are critical to the economies of all countries (Akhavan and Jafari, 2008), and especially the developing ones (Fathian, Akhavan and Hoorali, 2008; Gadenne and Sharma, 2009; Andreopoulou, Koliouska and Tsekouropoulos, 2012). SMEs in Greece are using e-business not only to enable growth through extended and refined offerings but also to expand their markets (Kindstrom and Brege, 2008). SMEs that have already adopted e-marketing applications may vary significantly in terms of the scope and extent of incorporating e-business applications into their business processes and benefiting from them (Wand and Shi, 2009).

In Greece, specifically in the sector of food and drink several enterprises have already a presence in the internet. That facilitates the increase of their total sales as they attract costumers not only locally at shops but also on the e-shops in the internet. There are also enterprises without physical shop for holding transactions with the public thus they exist only in the internet (Seretakis, Tsekouropoulos, and Andreopoulou, 2010).

A literature review on internet adoption in Greek agri-food enterprises is also described by Manthou, Matopoulos and Vlachopoulou (2005), while a literature review on e-business adoption is described by Fritz and Canavari (2008), by Matopoulos, Vlachopoulou and Manthou (2009). An extensive literature review that concerned the Business-To Business relationships journal articles that were published between 2009 and 2012 was presented by Meixner et al. (2009), Canavari et al. (2010) and by Saprikis and Vlachopoulou (2012). However, a multicriteria analysis on evaluating the performance of Greek agricultural enterprises has been applied by Baourakis et al. (2002) and by Kalogeras et al. (2005).

This paper provides the case study of e-marketing and internet adoption by the agro-food and drink SME sector in Greece. Therefore, the paper aims to optimize and evaluate the Greek SMEs in agrofood and drink sector, qualitatively and quantitatively according to e-marketing features and internet functions used as criteria, based on the multicriteria method of PROMETHEE II and further to classify them in groups. Finally we identify and describe the optimum group of SMEs to be used as a model with enhanced customer communication policies.

\section{Methodology}

The SME websites of the Greek agro-food and drink sector were retrieved using the large-scale hypertextual search engine "Google" which provides much more satisfying results than other existing search engines (Berry and Browne (2005), Langville and Meyer (2006)). Some of the keywords that were used are: e-marketing, agro-food and drink, website activities, e-shop, e.t.c.. The study was conducted in 2011. 
Initially, qualitative analysis was performed in order to examine the type of common characteristics that is found in these corporate websites. There are various material website characteristics introduced in the retrieved websites, aiming to promote the enterprise involved. These criteria/characteristics are further attributed to variables X1 to Xn that describe a group of common website characteristics. The typical qualitative analysis and evaluation of the content introduced in the Greek SME websites identified 6 different types of characteristics and they are presented in Table 1. Yet, the number of characteristics could possibly vary according to the special thematic and the relative penetration in the market.

Table 1. Variables attributed to e-marketing services to be achieved by each website

\begin{tabular}{|c|c|}
\hline Variable & E-marketing services \\
\hline $\mathrm{X}_{1}$ & Autonomous internet presence \\
\hline $\mathrm{X}_{2}$ & Quality policy / Quality certificate \\
\hline $\mathrm{X}_{3}$ & Provision of product information to consumers \\
\hline $\mathrm{X}_{4}$ & Links to other companies etc \\
\hline $\mathrm{X}_{5}$ & Online communication form / FAQ \\
\hline $\mathrm{X}_{6}$ & E-shop \\
\hline
\end{tabular}

Then, a quantitative analysis was carried out, in order to examine the presence or absence of these criteria/characteristics. Additionally, a 2-dimentional table was developed and was used in order to examine the existence of criteria and evaluate the services of the websites.

Whenever a criterion was achieved for a website the value 1 was attributed to the respective variable aiming at justifying the relative service within the evaluation of the website.

The total amount of e-marketing criteria achieved in each website was also studied. For each food and drink enterprise website, the total number of achieved criteria is attributed to a new variable, named $t$. Variable $t$ presents the sum of e-marketing services achieved, therefore takes a value between 1 and 6.

Then, the total ranking of the websites was studied. The method that was used for the total ranking was the multicriteria analysis named PROMETHEE II. That method applies a linear form of service in the particular case, using the e-marketing services of the websites identified as criteria. The PROMETHEE II method is part of outranking relations theory (Brans and Vicke 1985; Brans, Vincke, and Mareschal, 1986; Siskos and Zopounidis, 1987; Brans et al., 1987; Brans et al., 1998; Zopounidis, 2001). A similar multicriteria method was used for the total ranking of websites for agricultural products (Andreopoulou et al., 2008). The PROMETHEE II method for multi criteria analysis uses six types of general criteria with the corresponding criteria services, in order to determine the superiority (outranking) between two alternative solutions.

In this specific case, the aim was to determine the superiority of one website over another website. The general level test criterion was selected for this project, corresponding to a criterion service, which has an interval region for the determination of superiority (Brans and Vicke, 1985; Roy, 1991). The websites that were retrieved in the internet concerning enterprises in food and drinks sector were examined in pairs as alternative solutions (ki, kj) with $i=1,2,66$ and $j=1,2 \ldots \ldots .66$ as to their supremacy, i.e. which of the two websites excelled based on the criteria used.

The service H (d), which was used to express superiority, was the following: 


$$
P(v i, v j) \text {, outranking of website vi, if } d \geq 0
$$

$$
H(d)=\{
$$

$P(v j, v i)$, outranking of website $v j$, if $d<0$

Where $\mathrm{P}\left(\mathrm{v}_{\mathrm{i}}, \mathrm{v}_{\mathrm{j}}\right), \mathrm{P}\left(\mathrm{v}_{\mathrm{j}}, \mathrm{v}_{\mathrm{i}}\right)$ are the services of preference, and $\mathrm{d}$ is the difference between the values of each pair of websites $\left(\mathrm{v}_{\mathrm{i}}, \mathrm{v}_{\mathrm{j}}\right)$, for the criterion under evaluation. When we examined which of the two websites $\left(\mathrm{v}_{\mathrm{i}}, \mathrm{v}_{\mathrm{j}}\right)$ is superior, the superiority service $\mathrm{H}(\mathrm{d})$ was applied according to the value $\mathrm{d}$ (positive or negative) for each criterion.

In this study, variables $\mathrm{X}_{1}, \ldots ., \mathrm{X}_{6}$ were used, which are the criteria described in Table 1 . The variables are unambiguous and are marked with either 0 or 1 . For this reason, the service used is of linear form $\rho=1$.

The multicriteria indicator of preference $\Pi\left(\mathrm{v}_{\mathrm{i}}, \mathrm{v}_{\mathrm{j}}\right)$ which is a weighted mean of the preference services $P\left(v_{i}, v_{j}\right)$ with weights $w_{i}$, express the superiority of website $v_{i}$ against website $v_{j}$ after all the criteria have been tested.

The values of $\Pi\left(\mathrm{v}_{\mathrm{i}}, \mathrm{v}_{\mathrm{j}}\right)$ are calculated using the following equation (Brans, Vincke, and Mareschal, 1986):

$$
\Pi\left(v_{i}, v_{j}\right)=\frac{\sum_{t=1}^{k} W_{t} \cdot \mathrm{P}_{t}\left(v_{i}, v_{j}\right)}{\sum_{t=1}^{k} W_{t}}
$$

We receive 50 scenarios of weights (one scenario of weights $\mathrm{w}_{\mathrm{i}}$ corresponds to all criteria) and for each scenario of weights we receive 10 scenarios on the standard deviation for every criterion. In total, we have 500 different net flow values for each website of food and drinks sector enterprise. We use the average of these 500 values as the final net flow value for each website of enterprise.

$\mathrm{K}$ is defined as the number of criteria and $\mathrm{P}_{\mathrm{t}}\left(\mathrm{v}_{\mathrm{i}}, \mathrm{v}_{\mathrm{j}}\right)$ the preference services for the $\mathrm{k}$ criteria. The multicriteria preference indicator $\Pi\left(\mathrm{v}_{\mathrm{i}}, \mathrm{v}_{\mathrm{j}}\right)$ takes values between 0 and 1 . When two websites $\left(\mathrm{v}_{\mathrm{i}}, \mathrm{v}_{\mathrm{j}}\right)$ are compared, one is assigned two flow values: outgoing flow and incoming flow. The outgoing flow is calculated by the following equation (Baourakis et al., 2001):

$$
\Phi^{+}\left(v_{i}\right)=\sum_{v_{j} \in A} \Pi\left(v_{i}, v_{j}\right)
$$

In both cases, $\mathrm{A}$ is defined as the number of alternative solutions for websites $\mathrm{v}_{\mathrm{j}}$. The outgoing flow expresses the total superiority of website $v_{i}$ against all other websites $v_{j}$ for all criteria. The incoming flow is determined by the following equation (Baourakis et al., 2001):

$$
\Phi^{-}\left(v_{i}\right)=\sum_{v_{j} \in A} \Pi\left(v_{i}, v_{j}\right)
$$

The incoming flow expresses the total superiority of all other websites $\mathrm{v}_{\mathrm{i}}$ against website $\mathrm{v}_{\mathrm{j}}$ for all criteria. The net flow for each website $v_{i}$ is estimated by the following formula:

$$
\Phi\left(v_{i}\right)=\Phi^{+}\left(v_{i}\right)-\Phi^{-}\left(v_{i}\right)
$$

The net flow is the final number that is used for the comparison between the websites in order to obtain the ranking. The ten values (scenarios) range between $0.25 \mathrm{~s}$ and $2.5 \mathrm{~s}$ with step $0.25 \mathrm{~s}$, where $\mathrm{s}$ is the standard deviation of all differences $d$ for each criterion. In total, we take 500 net flow values for 
each website and find the website's average value. Each website with a higher net flow is considered superior in the final ranking. Finally, they were classified in groups according to their net flow.

The PROMETHEE II methodology was selected in order to perform evaluation and ranking tasks, for the following reasons (Zopounidis, 2001):

a. because the estimated relation of superiority (of one website over another) is less sensitive in small changes and that offers an easier analysis and discussion of the results

b. the use of the superiority relation in the PROMETHEE method is applied when the alternative solutions (websites) have to be ranked from the best to the worst

c. the procedure of assessing and ranking complicated cases of websites is proper for the application of the above methodology in the sense that it is closer to reality.

In fact, there exist two types of the PROMETHEE methodology, the PROMETHEE I that ranks partially and also, the PROMETHEE II, which performs a full and complete ranking, based on all of the input data. The PROMETHEE II methodology was applied in this project because an overall ranking was required. It is also important that our variables concern qualitative data and PROMETHEE II methodology can successfully deal with that prerequisite (Koutroumanidis, Iliadis, and Arabatzis, 2004; Andreopoulou, Kokkinakis, and Koutroumanidis, 2009).

Moreover, regarding the application of PROMETHEE II in the field of agriculture and environment, there are recent research papers in Greece where the method is successfully applied (Koutroumanidis, Papathanasiou and Manos, 2002; Polyzos and Arabatzis, 2006; Andreopoulou et al., 2008; Tsekouropoulos et al., 2012a; Tsekouropoulos et al., 2012b).

The PROMETHEE methodology fits better to the targets of the project even if it is compared to other well-established methods. For example the ELECTRE methods are methods of superiority that use the rule of majority inside a relation of superiority. The target in the ELECTRE is to determine an alternative website, which is relatively "good", based on a majority of criteria without been too "bad" according to the rest of the criteria. Nevertheless this is not the objective of this project where the objective is the total evaluation of the websites. The AHP method is also well-known and broadly applied (Koutroumanidis, Iliadis, and Arabatzis, 2004). But, according to Alphonce (1997) the ability of the AHP to analyze different decision factors without the need for a common numerate, other than the decision maker's assessments, makes it one of the favorable multicriteria decision support tools when dealing with complex socioeconomic problems in developing countries.

\section{Results}

Research through search engines on the Greek internet resulted in the retrieve of 66 websites concerning enterprises in the Greek agro-food and drink sector that have an internet presence through a website.

In Figure 1, the achievement of each one of the 6 e-marketing services, expressed in variables $\mathrm{x}_{1}$ to $\mathrm{x}_{6}$ is presented. 


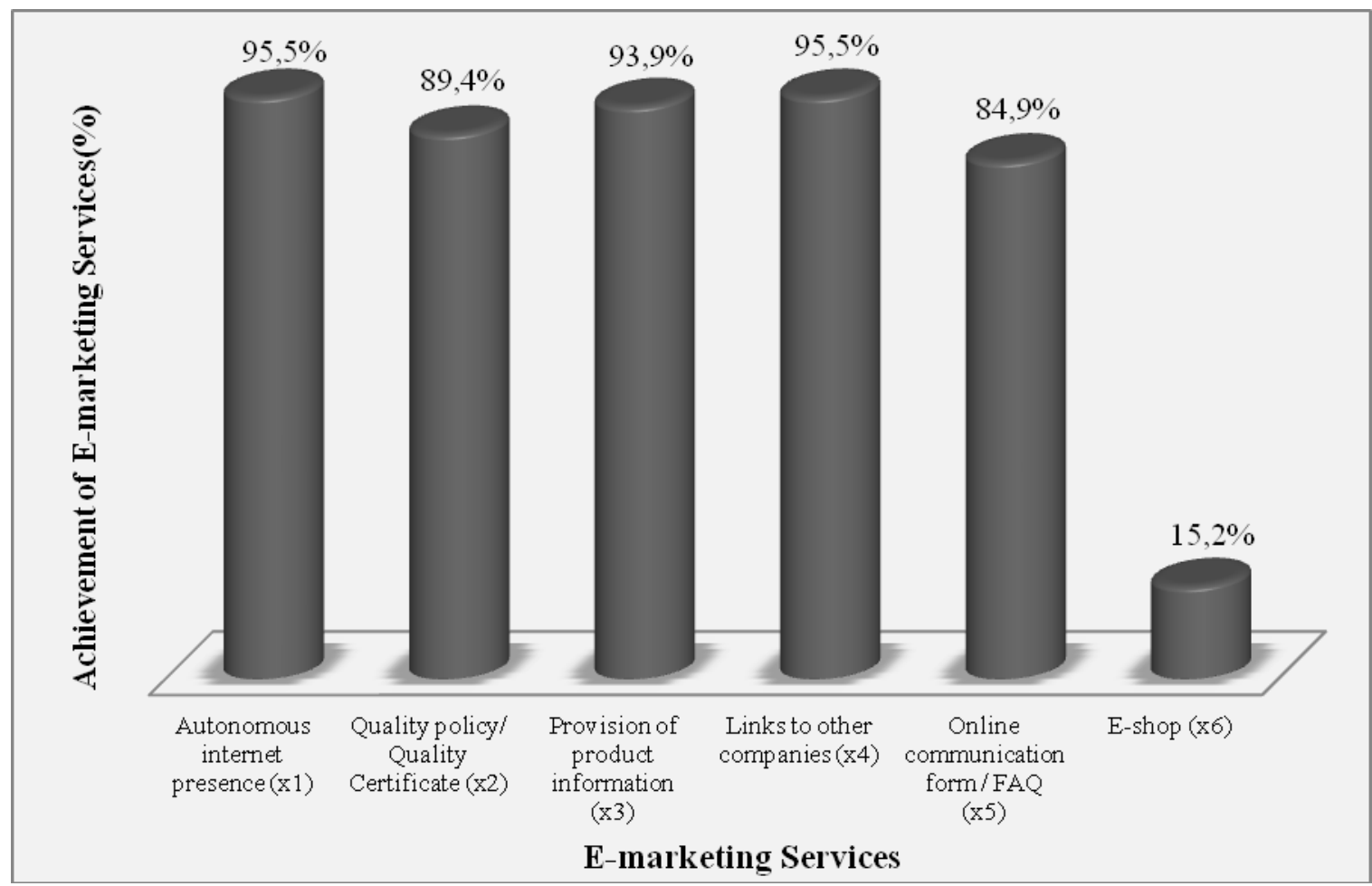

Figure 1. Achievement of e-marketing criteria about the SME websites

Regarding physical and internet presence of an enterprise $\left(\mathrm{x}_{1}\right), 95.5 \%$ of them fulfill that criterion.

Quality certificates for the agro-food and drink products are promoted through the enterprise website in $89.4 \%$ of the sample and so as the reliability of the recipes. These services often go hand in hand and are represented with variable $\mathrm{x}_{2}$.

Most enterprises $(93.9 \%)$ promote their products by providing various information to the consumers. E-promotion of the products is shown through variable $\mathrm{x}_{3}$.

Concerning now the feature about the presence or the absence of other links in the website of each enterprise, represented with variable $\mathrm{x}_{4}, 95.5 \%$ of the enterprises offer the possibility of access in other websites.

Moreover, almost $85 \%$ of these enterprises, within the framework of qualitative policy applied, support the communication with the consumer through online communication forms $\left(\mathrm{x}_{5}\right)$ aiming to provide additional information for the products, services and transactions, to receive complaints, to give advice and to also support after sales service. There is also the function of Frequently Asked Questions (FAQ) for provision of further information.

Finally, variable $\mathrm{x}_{6}$ represents the capability of e-shopping through a shoppping cart. A shopping cart is a software application that typically runs on the computer where the website of the enterprise is located and allows the customers to do things such as searching for a product in the store catalogue, adding selected product to a basket and placing an order for it.

Regarding variable $t$, which is the sum of e-marketing services accomplished by the enterprise websites, they are shown in Figure 2. Only seven enterprises accomplishes all seven e-marketing services $(t=7)$. 48 enterprises of the sample accomplish six e-marketing criteria $(t=6)$ while seven enterprises accomplish five characteristics $(t=5)$. Moreover, one enterprise accomplishes four emarketing services $(t=4)$ and three enterprises accomplish only one characteristics $(t=1)$. Finally, none of the enterprises accomplish two $(\mathrm{t}=2)$ or three $(\mathrm{t}=3)$ e-marketing services. 


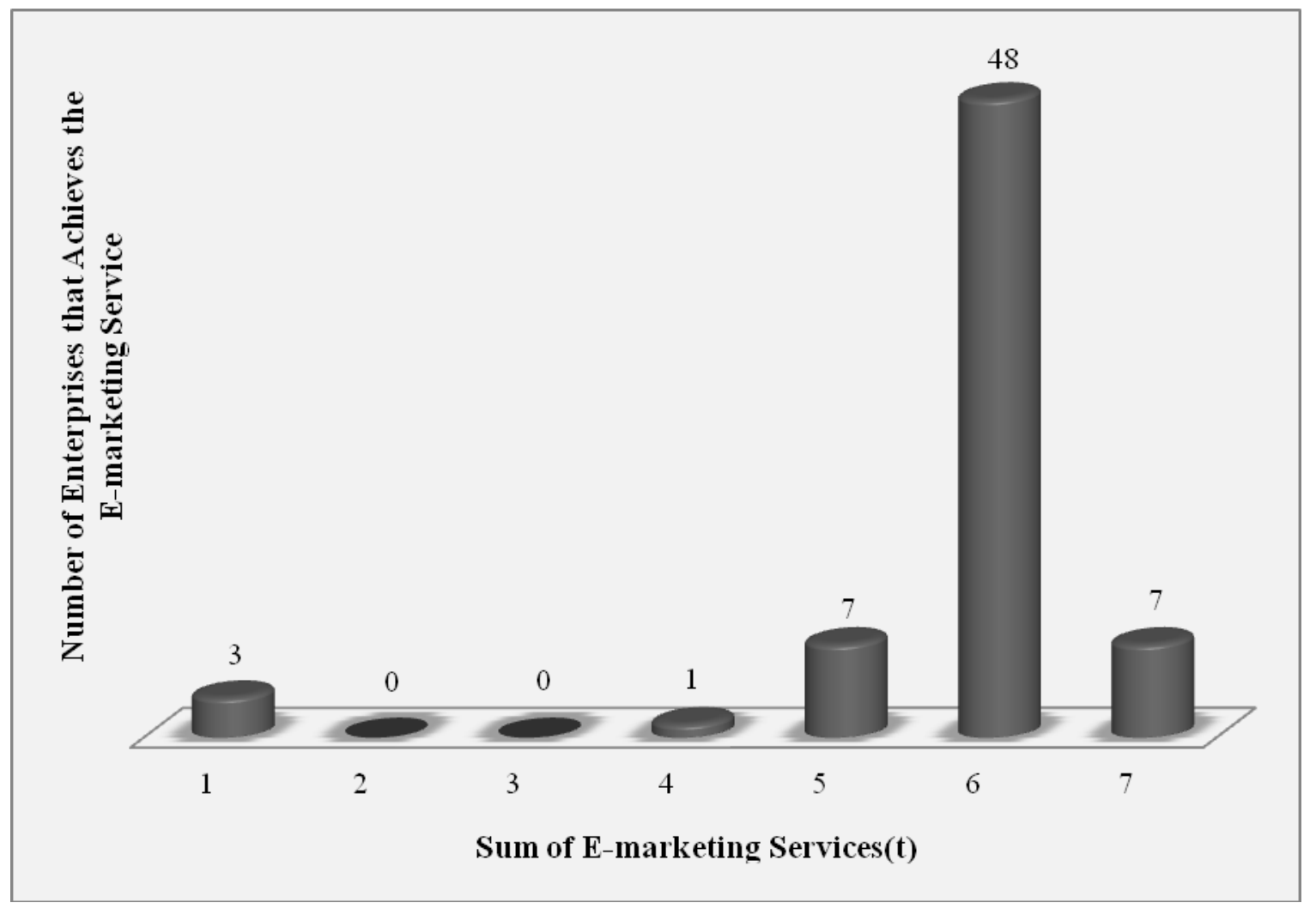

Figure 2. Sum of the e-marketing services accomplished by enterprises

\subsection{Ranking and classifying e-shops websites using the multicriteria method PROMETHEE II}

Based on the multicriteria analysis method PROMETHEE II, the total ranking of the e-shop websites is presented in Appendix (Table 1). In the same Table it is also presented the total net flow that is estimated for each website and it is used for the comparison between the websites in order to obtain the total ranking, as each website with a higher net flow is considered superior in ranking. Also, I the same table, the sum of the achieved criteria for each website and the classification in groups appear.

According to these findings, the values that were estimated for the total net flows $\Phi$ present a great spectrum of values between $(+9.936)$ to $(-47.846)$ and that indicates a great difference concerning the 'superiority' between the first and last case in the ranking of the enterprises' websites. Moreover, the total flows $\Phi$ of the enterprises' websites, as derived from the application of the PROMETHEE II method, allow a further grouping of the cases and generate four groups (Figure 3):

- Group 1: In this group, 8 enterprise websites are classified, that achieve 5-6 e-marketing services and very high total flows (+9.936) to (6.943) that present a "high superiority" against the rest of the cases.

- Group 2: In this group, 47 websites of the enterprises are classified, that achieve 5 e-marketing characteristics and medium total flows $(+3.218)$ to $(0.466)$ that present a 'low superiority' against the rest of the cases.

- Group 3: In this group, 6 enterprise websites are classified in this group, that achieve 4 emarketing characteristics and average negative total flows $(-0.426)$ to $(-3.156)$ that present an 'average lag' against the rest of the cases.

- Group 4: In this group, 5 websites are classified, that achieve 0-4 e-marketing services and average negative total flows $(-8.478)$ to $(-47.846)$ that present a 'high lag' against the rest of the cases. 


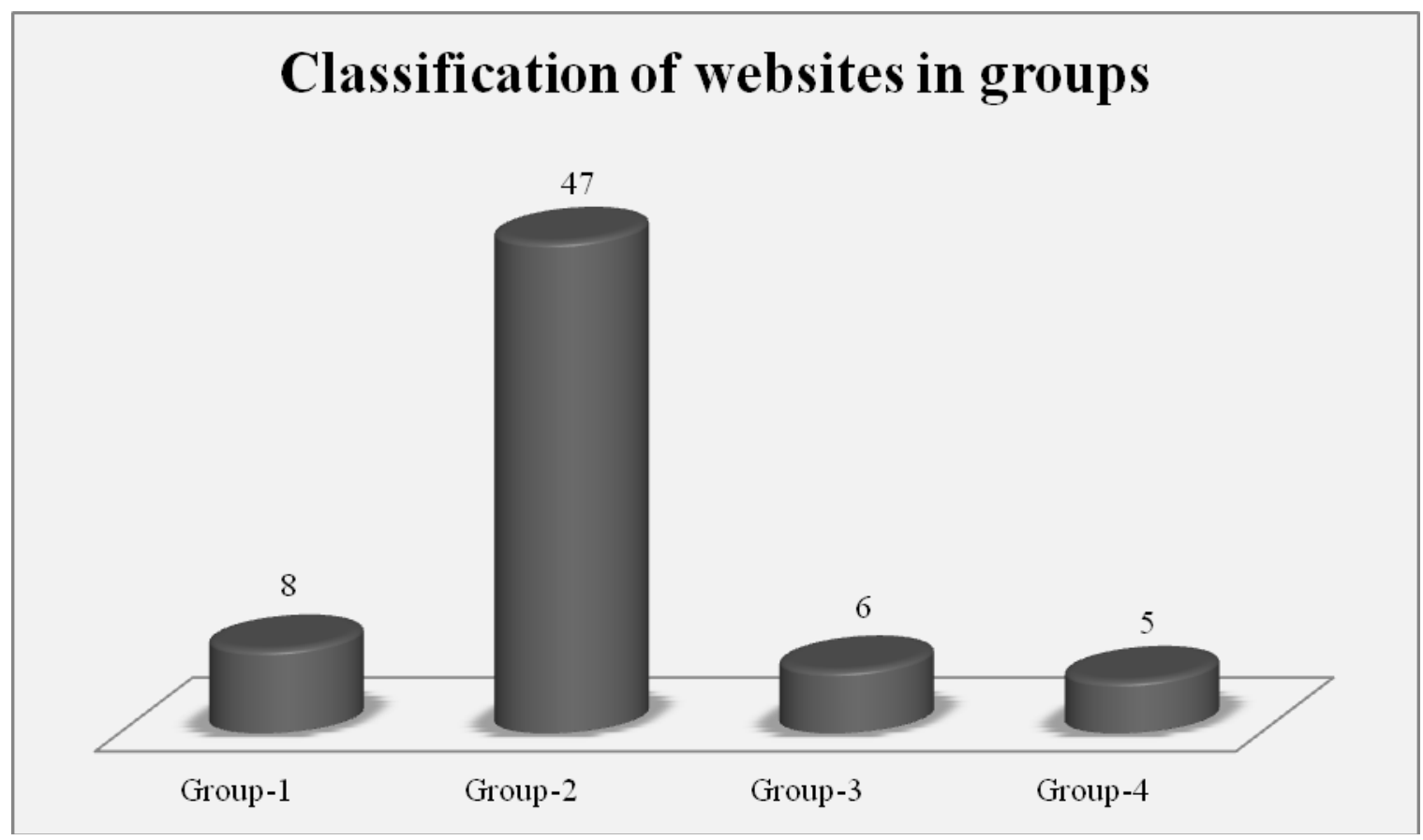

Figure 3. Classification of enterprise websites in groups according to their total Net flow

\section{Conclusions}

Internet has become a most effective means for promoting and enhancing purchasing via the promotion of products and the provision of any possible information existing, before selling. Also it contributes in facilitating the customers when buying and ordering, it helps financial transactions, secures delivering of products and preserves the prestige of the company while keeping clients satisfied after sales service (Andreopoulou, Koutroumanidis, and Manos, 2009).

Internet research has retrieved 66 websites that represent Greek SME in agro-food and drink sector. With the aim of studying the adoption of e-marketing and internet services, the websites were qualitative studied and 6 different characteristics that promote e-marketing and e-commerce activities.

Findings show that the majority of the websites achieve 5 criteria while $83 \%$ of the enterprise websites achieve 5-6 e-marketing and internet services. Quality certificates for the agro-food and drink products are promoted through the $89.4 \%$ of the websites. E-promotion of the products is found in $93 \%$ of the enterprise websites.

Most websites (47) were classified in the second group, that presents low superiority. In the third and the fourth group, $17 \%$ of the cases are classified, which means that few websites present a lag, achieve few criteria and occupy negative total net flows. The enterprises, that belong to these groups, should be optimized considering group 1 as a model. Although only $12 \%$ of the enterprise websites are classified in the first group and achieve 5-6 e-marketing services, they consequently appear to have a high superiority against the rest of the cases, representing a high level of e-commerce and e-marketing adoption.

According to the findings, the values that were estimated for the total net flows $\Phi$ present a great spectrum of values and that points out a great difference that concerns the 'superiority' between the first and last case in the ranking of the enterprises' websites. Besides, the total net flows $\Phi$ of the enterprises' websites, as derived from the application of the PROMETHEE II method, allow a further grouping of the cases and the initial creation of four groups, plus a single case that would be considered as the fifth group.

The results of this study can be an efficient tool while designing similar websites for an enterprise aiming to initially or further involve itself in the e-commerce/e-marketing activities in the agro-food 
and drink sector. Therefore, it is pointed out that these Greek enterprises have to adjust to the new 'information era' and aim to become more effective while accomplishing e-marketing activities. As the majority of the enterprises in this sector are generally still in the initial adoption stage (usually a promotional level), they should further mature in the next stages of e-commerce adoption, as those stages of adoption characterized for their dynamic interaction with potential clients and finally, the total integration of e-commerce activities and the optimization of the supply chain. The findings are useful in improving e-commerce adoption through the improved design and implementation of a website to fulfil certain features and characteristics.

\section{References}

Akhavan, P. and M. Jafari. 2008. Towards learning in SMEs: An empirical study in Iran. Development and Learning in Organizations. 22(1):17-19.

Alphonce, B.C. 1997. Application of the analytic hierarchy process in agriculture in developing countries. Agricultural Systems. 53:97-112.

Andreopoulou, Z. 2012. Green Informatics: ICT for Green and Sustainability. Journal of Agricultural Informatics. 3(2): 1-8.

Andreopopulou, Z., A. Kokkinakis and T. Koutroumanidis. 2009. Assessment and optimization of e-commerce websites of fish culture sector. Operational research: An international journal. 9(3):293-309.

Andreopoulou, Z.S., C. Koliouska and G. Tsekouropoulos. 2012. Strategic planning and decision support in small-medium wood enterprises using database technology. Journal of Agricultural Informatics. 3(1):36-45.

Andreopoulou , Z., T. Koutroumanidis and B. Manos. 2009. The adoption of e-commerce for wood enterprises. International Journal of Business Information Systems. 4(4):440-459.

Andreopoulou, Z., G. Tsekouropoulos, T. Koutroumanidis, M. Vlachopoulou and B. Manos. 2008. Typology for e-business activities in the agricultural sector. International Journal of Business Information Systems. 3(3):231251.

Baghdadi, Y. 2006. Architecture for deploying e-business: business processes, web services-business interactions manager, and information systems. International Journal of Electronic Business. 4(1):18-39.

Baourakis, G., M. Doumpos, N. Kalogeras and C. Zopounidis. 2002. Multicriteria analysis and assessment of financial viability of agribusinesses: The case of marketing co-operatives and juice-producing companies. Agribusiness. 18(4):543-558.

Baourakis, G., N. Kalogeras, M. Doumpos, C. Stavropoulos, M. Bankova, and C. Zopounidis. 2001. Multicriteria methodology of evaluation of financing records of enterprises of rural sector: The case of the cooperative and juice enterprises. In Analysis of Financing Decisions with Multiple Criteria in Zopounidis, C. ed., 317-333. Anikoula Publications, Thessaloniki,.

Berry, M.W. and M. Browne. 2005. Understanding Search Engines: Mathematical Modeling and Text Retrieval. Society for Industrial Mathematics.

Brans, J. P., A. Chevalier, P. Kunsch, C. Macharis and M. Schwaninger. 1998. Combining multicriteria decision aid and system dynamics for the control of socio-economic processes. European Journal of Operational Research. 109:428-441.

Brans, J. P., B. Mareschal, J. Margeta and N. Mladineo. 1987. Multicriteria ranking of alternative locations for small scale hydro plants. European Journal of Operational Research. 31:215-222.

Brans, J. P., P. Vincke and B. Mareschal. 1986. How to select and how to rank projects: The PROMETHEE method. European Journal of Operational Research. 24:228-238.

Brans, J. P. and P. Vincke. 1985. A preference ranking organization method: The PROMETHEE method for multiple criteria decision making. Management Science. 31(6):647-656.

Buhalis, D. and R. Law. 2008. Progress in information technology and tourism management: 20 years and 10 years after the internet - The state of e-tourism research. Tourism Management. 29:609-623.

Bui, T., T. Le and W. Jones. 2006. An exploratory case study of hotel e-marketing in Ho Chi Minh city. Thunderbird International Business Review. 48(3):369-388. 
Burgess, S., C. Sellito and A. Wenn. 2005. Maturity in the websites of Australian wineries: A study of varying website content. International Journal of Electronic Business. 3(5):473-490.

Cai, L., J. Card and S. Cole. 2004. Content delivery performance of world wide web sites of US Tour operators focusing on destinations in China. Tourism Management. 25:219-227.

Calitz, A., and B. Sheepers. 2002. A comparative analysis of e-commerce website development using two implementation methods. In Proc. of the Conference of the South African Institute of Computer Scientists and Information Technologists on Enablement through Technology 2002 (SAICSIT 2002), 251, South African Institute of Computer Scientists and Information Technologists, Port Elizabeth, Republic of South Africa.

Canavari, M., M. Fritz, G.J. Hofstede, A. Matopoulos, and M. Vlachopoulou. 2010. The role of trust in the transition from traditional to electronic B2B relationships in agri-food chains. Computers and Electronics in Agriculture. 70(2):321-327.

Chan, M.S., and W.C. Chung. 2002. A framework to develop an enterprise information portal for contract manufacturing. International Journal of Production Economics. 74:113-126.

Department of Trade and Industry of United Kingdom. 2004. Achieving best practice in your business. Emarketing.

DigitSmith. 2006. Ecommerce definition and types of Ecommerce. Available at: http://www.digitsmith.com/ecommerce-definition.html.

Eszes, I. 2010. An introduction to Internet marketing. Available at: http://www.eszes.net

Fathian, M., P. Akhavan, and M. Hoorali. 2008. E-readiness assessment of non-profit ICT SMEs in a developing country: The case of Iran. Technovation. 28(9):578-590.

Fritz, M., and M. Canavari. 2008. Management of perceived e-business risks in food supply networks: e-trust as prerequisite for supply chain system innovation. Agribusiness. 24(3):355-368.

Gadenne, D. and B. Sharma. 2009. Management factors of Australian SMEs and their association with firm performance. International Journal of Quality \& Reliability Management. 26(9):865-880.

Garces, S., S. Gorgemans, M. Sanchez, and M. Perez. 2004. Implications of the internet - An analysis of the Aragonese hospitality industry. Tourism management. 25:603-613.

Gunasekaran, A., and E.W.T. Nagai. 2007. Managing digital enterprise. International Journal of Business Information Systems. 2(3):266-275.

Ha, L., and G. Forgionne. 2008. The establishment of an e-business strategy model from traditional theories. International Journal of Electronic Business. 6(4):354-368.

Kalogeras, N., G. Baourakis, C. Zopounidis, and G. Van Dijk. 2005. Evaluating the financial performance of agri-food firms: a multicriteria decision-aid approach. Journal of Food Engineering. 70(3):365-371.

Kindstrom, D., and S. Brege. 2008. The next step for e-business among mature and established companies: a focus on revenue and differentiation instead of costs. International Journal of Electronic Business. 6(5):462-475.

Koutroumanidis T., I. Papathanasiou, and B. Manos. 2002. A multicriteria analysis of productivity of agricultural regions of Greece. Operational research: An International Journal. 2(3):339 - 346.

Koutroumanidis, T., L. Iliadis, and G. Arabatzis. 2004. Evaluation and forecasting of the financial performance of the rural cooperatives by a Decision Support System. Japanese Journal of Rural Economics. 6:31-44.

Krueger, C.C., and P.M.C. Swatman. 2004. Developing e-business models in practice: The case of the regional online newspaper. International Journal of Information Technology and Management. 3(2-4):157-172.

Langville, A.N. and C.D. Meyer. 2006. Google's Pagerank and Beyond: The Science of Search Engine Rankings. Princeton University Press.

Law, R., and C. Hsu. 2005. Customer's perceptions on the importance of hotel web site dimensions and attributes. International Journal of Contemporary Hospitality Management. 17(6):493-503.

Lee, G., L. Cai, and J. O’Leary. 2006. Www.branding.states.us: An analysis of brand-building elements in the US state tourism websites. Tourism management. 27:815-828.

Liang, K., and R. Law. 2003. A modified functionality performance evaluation model for evaluating the performance of China based hotel websites. Journal of the Academy of Business and Economics. 2(2). Available at: http://www.findarticles.com/p/articles/mi_hb3198/is_200304/ai_n7873374 
Manthou, V., A. Matopoulos, and M. Vlachopoulou. 2005. Internet-based applications in the agri-food supply chain: A survey on the Greek canning sector. Journal of Food Engineering. 70(3):447-454.

Marri, H.B., Z. Irani, and A. Gunasekaran. 2007. Advance Manufacturing Technology implementation in SMEs: a framework of justification criteria. International Journal of Electronic Business. 5(2):124-140.

Matopoulos, A., M. Vlachopoulou, and V. Manthou. 2009. Understanding the factors affecting e-business adoption and impact on logistics processes. Journal of Manufacturing Technology Management. 20(6):853-865.

Meixner, O., C. Ameseder, R. Haas, M. Canavari, M. Fritz, and G.J. Hofstede. 2009. Importance of trust building elements in business-to-business agri-food chains. Journal of Farm Management. 13(9):655 - 668 .

O’ Connor, P. 2007. Online consumer privacy: an analysis of hotel company behavior. Cornell Hotel and Restaurant Administration Quarterly. 48(2):183-200.

Petrovic, D. 2010. What is e-Marketing?Available at:http://analogik.com/articles/231/e-marketing.

Polyzos, S, and G. Arabatzis. 2006. Multicriteria approach of the Greek prefectures evaluation according to tourist resources. Tourism Today. 96-111.

Quirk eMarketing. 2006. What is e-marketing and how is it better than traditional marketing?. Available at: http://www.quirk.biz

Reuver, M., H. Bouwman, and I. Maclnnes. 2009. Business models dynamics for atart-ups and innovating ebusinesses. International Journal of Electronic Business. 7(3):269-286.

Roy, B. 1991. The outranking approach and the foundations of ELECTRE methods. Theory and Decision. 31:49-73.

Saprikis, V., and M. Vlachopoulou. 2012. Determinants of suppliers' level of use of B2B e-marketplaces. Industrial Management and Data Systems. 112(4):619-643.

Seretakis, A., G. Tsekouropoulos, and Z. Andreopoulou. 2010. Study on the rate of e-commerce activities presence of Greek enterprises in food and drinks sector. Greek Company of Information and Communications in Agriculture (EPEGE), January 2010, $3^{\text {rd }}$ Volume of Scientific Works: E-business applications on the agricultural sector, 1.

Siskos, J., and C. Zopounidis. 1987. The evaluation criteria of the venture capital investment activity: An interactive assessment. European Journal of Operational Research. 31:304-313.

Soto-Acosta, P., and A.L. Merono-Cerdan. 2006. An analysis and comparison of web development between local governments and SMEs in Spain. International Journal of Electronic Business. 4(2):191-203.

The National B2B Centre. 2011. Develop an e-marketing plan. Available at: http://www.businesslink.gov.uk

Tsekouropoulos, G., Z. Andreopoulou, C. Koliouska, T. Koutroumanidis, C. Batzios, and P. Lefakis, P. 2012 a. Marketing Policies Through The Internet: The Case Of Skiing Centers In Greece. Scientific Bulletin-Economic Sciences. 11(1):66-78.

Tsekouropoulos, G., Z. Andreopoulou, A. Seretakis, T. Koutroumanidis, and B. Manos. 2012b. Optimizing Emarketing Criteria for Customer Communication in Food and Drink Sector in Greece. International Journal of Business Information Systems. 9(1):1-25.

Tsekouropoulos, G., I. Tzimitra-Kalogianni, and B. Manos. 2005. Logistics in Greek agricultural enterprises Problems - Prospects. In Proc. ITAFE-05 International Conference on Information Technology in Agriculture, Food and Environment, 1: 606-613,12-14 October 2005. Cukurova University, Adana, Turkey.

Wang, Y. and X. Shi. 2009. E-Business assimilation in SMEs of China. International Journal of Electronic Business. 7(5):512-535.

Zopounidis, C. 2001. Analysis of financing decisions with multiple criteria. Anikoula Publications, Thessaloniki. 


\section{Appendix}

Table 1. The total ranking of the websites, the total net flows of each website and the

\begin{tabular}{|c|c|c|c|}
\hline Final Ranking & URL of SME & Net flow $\Phi$ & Groups \\
\hline 1 & www.e-anemos.gr & 9,936 & group-1 \\
\hline 2 & www.foccacia.gr & 7,91 & group-1 \\
\hline 3 & www.aristeos.gr & 7,91 & group-1 \\
\hline 4 & www.agapitos.gr & 7,91 & group-1 \\
\hline 5 & www.absinthe.gr & 7,037 & group-1 \\
\hline 6 & www.agelidiscava.gr & 7,037 & group-1 \\
\hline 7 & www.cavaarion.gr & 7,037 & group-1 \\
\hline 8 & www.stivos.net & 6,943 & group-1 \\
\hline 9 & www.skouna.gr & 3,218 & group-2 \\
\hline 10 & www.tragakis.com & 3,218 & group-2 \\
\hline 11 & www.papmar.gr & 3,077 & group-2 \\
\hline 12 & www.helmos.com & 3,003 & group-2 \\
\hline 13 & www.golden-sandwich.gr & 3,003 & group-2 \\
\hline 14 & www.trofodosia.gr & 3,003 & group-2 \\
\hline 15 & www.mastfoods.com & 3,003 & group-2 \\
\hline 16 & www.provinco.gr & 3,003 & group-2 \\
\hline 17 & www.troficom.gr & 3,003 & group-2 \\
\hline 18 & www.pitenis.gr & 3,003 & group-2 \\
\hline 19 & www.aretousa.gr & 3,003 & group-2 \\
\hline 20 & www.AristonFoods.gr & 3,003 & group-2 \\
\hline 21 & www.thymiopoulos.gr & 3,003 & group-2 \\
\hline 22 & www.lena.com.gr & 3,003 & group-2 \\
\hline 23 & www.tropis.gr & 3,003 & group-2 \\
\hline
\end{tabular}




\begin{tabular}{|c|c|c|c|}
\hline 24 & www.biofresco.gr & 3,003 & group-2 \\
\hline 25 & www.bioshop.gr & 3,003 & group-2 \\
\hline 26 & www.arvanitis.gr & 3,003 & group-2 \\
\hline 27 & www.fikas.gr & 3,003 & group-2 \\
\hline 28 & www.metsovosa.gr & 3,003 & group-2 \\
\hline 29 & www.agrovim.gr & 3,003 & group-2 \\
\hline 30 & www.filippos-sa.gr & 3,003 & group-2 \\
\hline 31 & www.fresca.gr & 3,003 & group-2 \\
\hline 32 & www.chrisanidis.gr & 3,003 & group-2 \\
\hline 33 & www.elinos.gr & 3,003 & group-2 \\
\hline 34 & www.greek-ouzo.com & 2,53 & group-2 \\
\hline 35 & www.coffee-nettos.gr & 2,53 & group-2 \\
\hline 36 & www.ellvino.gr & 2,101 & group-2 \\
\hline 37 & www.pilavas.gr & 2,101 & group-2 \\
\hline 38 & www.karoniswineshop.gr & 2,101 & group-2 \\
\hline 39 & www.fileloinon.gr & 2,101 & group-2 \\
\hline 40 & www.kavapergola.gr & 1,928 & group-2 \\
\hline 41 & www.cava-semeli.gr & 1,928 & group-2 \\
\hline 42 & www.onassis-foods.gr & 1,879 & group-2 \\
\hline 43 & www.sisitis.gr & 1,879 & group-2 \\
\hline 44 & www.kordonismarket.gr & 1,879 & group-2 \\
\hline 45 & www.nektar.gr & 1,879 & group-2 \\
\hline 46 & www.amphion.gr & 1,879 & group-2 \\
\hline 47 & www.minosfoods.gr & 1,173 & group-2 \\
\hline 48 & www.melissa.gr & 1,173 & group-2 \\
\hline 49 & www.biotrofos.gr & 1,173 & group-2 \\
\hline 50 & www.elgeka.gr & 1,173 & group-2 \\
\hline 51 & www.sunspices.gr & 1,173 & group-2 \\
\hline
\end{tabular}




\begin{tabular}{|c|c|c|c|}
\hline 52 & Www.ionikigr.com & 1,173 & group-2 \\
\hline 53 & www.konva.gr & 1,173 & group-2 \\
\hline 54 & www.trofotechniki.gr & 1,173 & group-2 \\
\hline 55 & www.mi-alpha.gr & 0,466 & group-2 \\
\hline 56 & www.pikounis.gr & $-0,426$ & group-3 \\
\hline 57 & www.seafood.triton.gr & $-0,426$ & group-3 \\
\hline 58 & www.antonio.gr & $-2,512$ & group-3 \\
\hline 59 & www.aromathellas.gr & $-2,512$ & group-3 \\
\hline 60 & www.cava-sfetsiou.gr & $-3,156$ & group-3 \\
\hline 61 & www.boikos.gr & $-3,156$ & group-3 \\
\hline 62 & www.cibshellas.com & $-8,478$ & group-4 \\
\hline 63 & www.cookieman.gr & $-18,708$ & group-4 \\
\hline 64 & topalis@kar.forthnet.gr & $-40,495$ & group-4 \\
\hline 65 & mamas@mamas.gr & $-46,143$ & group-4 \\
\hline 66 & alcosa@otenet.gr & $-47,846$ & group-4 \\
\hline
\end{tabular}

